\title{
Studies on the Production of Low Density Lipoproteins by Perfused Livers from Nonhuman Primates
}

\author{
EFFECT OF DIETARY CHOLESTEROL
}

\author{
Fred L. Johnson, Richard W. St. Clair, and Lawrence L. Rudel, \\ Departments of Pathology and Comparative Medicine, \\ Bowman Gray School of Medicine of Wake Forest University, \\ Winston-Salem, North Carolina 27103
}

\begin{abstract}
A B S T R A C T Nonhuman primates consuming diets containing cholesterol develop coronary artery atherosclerosis that we have found to be highly correlated with an increase in the size and cholesteryl ester content of plasma low density lipoproteins (LDL). The present studies were designed to determine whether the enlarged plasma LDL are produced directly by the liver of cholesterol-fed monkeys. African green monkeys were fed a diet containing $40 \%$ of calories as butter fat and either $0.16 \mathrm{mg}$ cholesterol $/ \mathrm{kcal}$ (control diet) or $0.78 \mathrm{mg}$ cholesterol $/ \mathrm{kcal}$ (test diet). The livers of these monkeys were perfused by recirculation with a lipoprotein-free medium for $4 \mathrm{~h}$. The rate of accumulation of perfusate cholesterol was linear and greater in liver perfusates from test diet-fed vs. control diet-fed monkeys and was positively correlated with both the plasma cholesterol concentration and LDL size in the donor animal. All perfusate $d<1.063 \mathrm{~g} /$ $\mathrm{ml}$ lipoprotein subfractions from livers of test diet-fed monkeys were enriched in cholesteryl ester severalfold over the corresponding subfractions from control dietfed monkeys and contained only the larger form of apolipoprotein B typical of plasma LDL. However, the perfusate lipoproteins in the LDL density range did not have an average size or composition typical of LDL from plasma. Rather, they were relatively enriched in phospholipid and unesterified cholesterol and were deficient in cholesteryl esters. In addition, perfusate high density lipoproteins were discoidal particles. These data show that the enzyme lecithin:cholesterol acyltransferase (LCAT) was essentially inactive in
\end{abstract}

Received for publication 20 December 1982 and in revised form 9 March 1983. these perfusates and, as a result, the dietary cholesterol-induced enrichment of perfusate $d<1.063 \mathrm{~g} / \mathrm{ml}$ lipoproteins with cholesteryl esters probably resulted from increased hepatic secretion of cholesteryl esters and not from modification of lipoproteins by LCAT during recirculating perfusion. In spite of this increase, enlarged cholesteryl ester-rich LDL were not found in the perfusate, suggesting that large molecular weight plasma LDL are not directly secreted by the liver but instead probably result from further intravascular metabolism of cholesteryl ester-enriched hepatic precursor lipoproteins.

\section{INTRODUCTION}

The hypercholesterolemia that develops when nonhuman primates are fed a high-fat, high-cholesterol diet is consistently characterized by an increase in the molecular weight of plasma low density lipoprotein (LDL) $(1,2)$. The increase in LDL molecular weight has been found to be highly correlated with the severity of coronary artery atherosclerosis (2-4). Most of the increase in LDL size appears to be due to an increase in the cholesteryl ester content of the core of the particle, together with an increase in polar lipids and protein sufficient to maintain a $21-\AA$-thick coat (1).

The origin of the enlarged atherogenic LDL found in the plasma of monkeys fed a cholesterol-enriched diet is unknown. Numerous kinetic studies in rats (5) and humans (6) indicate that LDL can be derived from the catabolism of plasma very low density lipoproteins (VLDL), but it remains to be established whether all of the plasma LDL are derived from VLDL. Indeed, under certain hyperlipidemic conditions $(7,8)$ and in 
some nonhuman species $(9,10)$, plasma LDL appear to be produced by one or more mechanisms separate from the catabolism of VLDL. Several studies indicate that the liver may be a direct source of plasma LDL. Nakaya et al. $(11,12)$ demonstrated de novo synthesis and secretion of lipoproteins with LDL density by the isolated perfused pig liver. Swift et al. $(13,14)$ isolated a cholesteryl ester-rich LDL from the hepatic Golgi apparatus of cholesterol-fed rats, and Noel et al. (15) demonstrated production of a cholesteryl ester-rich LDL by the isolated perfused liver of cholesterol-fed rats. Guo et al. (16) have recently identified cholesteryl ester-rich LDL in perfusates of livers from normal and cholesterol-fed guinea pigs, but suggest that many of these particles represent washout from liver of adsorbed plasma LDL.

The purpose of the present study was to characterize the lipoproteins produced by isolated perfused livers of monkeys fed diets containing either low or high amounts of cholesterol to determine whether the large molecular weight LDL found in the plasma of monkeys fed high-cholesterol-containing diets were produced directly by the liver.

\section{METHODS}

Animals and diets. Adult male African green monkeys (Cercopithecus aethiops) of the vervet subspecies weighing 3.8-5.8 $\mathrm{kg}$ were purchased from an animal importer (Primate Imports Corp., Port Washington, NY). Two groups were established, according to the level of cholesterol in the diet. The diets fed to the animals have been described previously (see 75-8B diets, reference 17). The control diet contained $0.16 \mathrm{mg}$ cholesterol $/ \mathrm{kcal}$, while the test diet contained $0.78 \mathrm{mg}$ cholesterol $/ \mathrm{kcal}$. Each diet contained $40 \%$ of calories as butter fat. The animals were fed their respective diets for 24-60 mo before their livers were taken for perfusion. Throughout their time in the colony, the animals were monitored monthly for total serum and high density lipoprotein (HDL) cholesterol concentrations. All animals remained in good health throughout the study.

Perfusion of livers. Animals were fed 12-13 h before liver perfusion, which was begun between 9:30 a.m. and 10:30 a.m. Animals were restrained with ketamine hydrochloride (Bristol Laboratories Div., Bristol-Myers, Syracuse, NY, $25-50 \mathrm{mg} / \mathrm{kg}$ body $\mathrm{wt}$ ). A midline abdominal incision was made, and the liver was exposed. The common bile duct was cannulated with Tygon (Norton Co., Akron, $\mathrm{OH}$ ) microbore tubing, 0.040 in i.d. $\times 0.070$ in o.d. The hepatic artery was ligated, the portal vein was cannulated with Tygon R-3603 tubing, $1 / 16$ in i.d. $\times 1 / 8$ in o.d., and the liver was immediately flushed at $0.5 \mathrm{ml} / \mathrm{min}$ per g liver with oxygenated, erythrocyte-free medium. Liver weight was estimated as $2.2 \%$ of body weight for this purpose. The perfusion medium was pumped through the liver by a peristaltic roller pump (Masterflex, model no. 7565-10, Cole-Parmer Instrument Co., Chicago, IL) with pumphead (model no. 7017). The inferior vena cava was then ligated above the renal veins and severed below the ligature. The flush rate was immediately increased to $1 \mathrm{ml} /$ min per $g$ liver. The thorax was opened, and the thoracic inferior vena cava was cannulated with Tygon $1 / 8$ in i.d. $\times 3 / 16$ in o.d. tubing. The liver was excised, and the cystic duct was ligated. At this point, flow to the liver was briefly reduced to an absolute rate of $10 \mathrm{ml} / \mathrm{min}$, the weight of the liver was determined gravimetrically on a top-loading balance, and the flush rate was readjusted to $1 \mathrm{ml} / \mathrm{min}$ per $\mathrm{g}$ liver. This flow rate was maintained throughout the perfusion. The liver was suspended on a nylon screen in a closed plexiglass chamber. The temperature in the chamber was kept at $38^{\circ} \mathrm{C}$ by an external heat lamp that was controlled by a temperature regulator (Yellow Springs Instrument Co., Yellow Springs, $\mathrm{OH}$ ). The perfusate was oxygenated with $100 \% \mathrm{O}_{2}$ by passage through a Silastic tubing (Dow Corning Corp., Midland, MI) lung, modified from the prototype of Hamilton et al. (18) to contain eight 6-ft lengths of tubing in parallel. All tubing in the system was preflushed with 4-6 liters of distilled water before use. The perfusion medium was maintained at $38^{\circ} \mathrm{C}$ by a heat exchanger. Macroemboli were removed by a 25-mm filter holder (Millipore Corp., Bedford, MA) containing a support screen. A bubble trap was located in line just before the portal vein cannula. Lymph or seepage from the liver was continuously returned to a reservoir from which the recirculating perfusate was pumped.

To start an experiment, the liver was flushed with 1-1.5 liters of erythrocyte-free medium, after which perfusion by recirculation was begun with $300 \mathrm{ml}$ of fresh, complete medium containing erythrocytes. To minimize contamination of hepatic lipoproteins by plasma lipoproteins trapped within the liver, recirculation perfusion was performed for $90 \mathrm{~min}$, and the liver and entire apparatus were then flushed with 1-1.5 liters of fresh, erythrocyte-free medium. The flush medium was subsequently replaced with $300 \mathrm{ml}$ of fresh medium containing erythrocytes, and recirculation perfusion was carried out for an additional $4 \mathrm{~h}$.

The perfusion medium consisted of Krebs-Henseleit original Ringer bicarbonate (10) containing $0.1 \%$ (wt/vol) D-glucose (Sigma Chemical Co., St. Louis, MO), $\mathbf{0 . 2 \%}$ (vol/vol) essential amino acid mix with glutamine (Flow Laboratories, Inc., Rockville, MD), $0.2 \%$ (vol/vol) nonessential amino acid mix (Flow Laboratories), $10 \mu \mathrm{g} / \mathrm{ml}$ L-cysteine $\mathrm{HCl}$ (Sigma Chemical Co.), $100 \mathrm{U} / \mathrm{ml}$ penicillin G sodium (Sigma Chemical Co.), $50 \mu \mathrm{g}$ / $\mathrm{ml}$ streptomycin sulfate (Sigma Chemical Co.), $40 \mu \mathrm{U} / \mathrm{ml}$ insulin (Regular Iletin, Eli Lilly \& Co., Indianapolis, IN), and $\mathbf{5 0}$ $\mu \mathrm{g} / \mathrm{ml}$ hydrocortisone sodium succinate (Solu-Cortef, Upjohn Co., Kalamazoo, MI). It was gassed with $95 \% \mathrm{O}_{2}, 5 \% \mathrm{CO}_{2}$ to $\mathrm{pH}$ 7.4. Human type $\mathrm{O}$ erythrocytes were washed several times with an equal volume of $0.9 \%(\mathrm{wt} / \mathrm{vol}) \mathrm{NaCl}, 0.01 \%$ (wt/vol) D-glucose, $\mathrm{pH} \mathrm{7.4,} \mathrm{and} \mathrm{twice} \mathrm{with} \mathrm{the} \mathrm{perfusion} \mathrm{medium.} \mathrm{The}$ cells were added to the medium to give a final hematocrit of $22 \%$. The perfusate was replenished with $20 \mu \mathrm{U}$ insulin $/ \mathrm{ml}$ medium every $30 \mathrm{~min}$.

Liver viability was monitored by color, consistency, and the rates of oxygen uptake, urea production, bile production, and cholesterol secretion. $\mathrm{PO}_{2}, \mathrm{PCO}_{2}$, and $\mathrm{pH}$ were determined throughout the perfusion with Instrumentation Laboratory (Lexington, MA) electrodes (model 213 analyzer). The extent of hemolysis was determined by measuring the accumulation of free hemoglobin in the perfusate, as indicated by an increase in $O D$ at $415 \mathrm{~nm}$ relative to values of fresh medium, and also by decreases in perfusate hematocrit and perfusate total hemoglobin concentration. Hemoglobin was determined by the cyanmethemaglobin method on a Coulter hemoglobinometer (Coulter Electronics, Inc., Hialeah, FL). Urea nitrogen was determined by the enzymatic-conductivimetric rate method on the Beckman BUN Analyzer 2 (Beckman Instruments, Inc., Cedar Grove, NJ).

Lipoprotein isolation and fractionation. At the completion of each experiment, the perfusate was collected on ice and made to a final concentration of $1 \mathrm{mM} 5,5$-dithiobis-(2-nitrobenzoic acid), to inhibit lecithin:cholesterol acyltransferase 
(LCAT), ${ }^{1} 0.1 \%$ EDTA, $0.1 \% \mathrm{NaN}_{3}, \mathrm{pH} 7.4$, and erythrocytes were then removed by centrifugation. All solutions subsequently used for lipoprotein isolation contained 0.01\% EDTA and $0.02 \% \mathrm{NaN}_{3}$. Perfusate lipoproteins were then isolated by either of two methods. In the first procedure, the density of the perfusate was raised to $1.225 \mathrm{~g} / \mathrm{ml}$ by the addition of solid $\mathrm{KBr}$, and perfusate lipoproteins were floated by ultracentrifugation for $40 \mathrm{~h}$ at $60,000 \mathrm{rpm}, 4^{\circ} \mathrm{C}$, in a $60 \mathrm{Ti}$ rotor (Beckman Instruments, Inc.) using a model L2-65B ultracentrifuge (Beckman Instruments, Inc.). The tubes were sliced and the top fraction containing the lipoproteins was removed. The lipoproteins were then washed and concentrated by recentrifugation at the same density. In the second method, used in the majority of cases, VLDL $(d<1.006 \mathrm{~g} / \mathrm{ml}$ lipoproteins) were initially isolated by ultracentrifugation of the perfusate for $18 \mathrm{~h}$ at 60,000 $\mathrm{rpm}$ in the $60 \mathrm{Ti}$ rotor. The density of the infranate was then raised to $1.225 \mathrm{~g} / \mathrm{ml}$ as before, and $1.006<d<1.225 \mathrm{~g} / \mathrm{ml}$ lipoproteins were floated by ultracentrifugation as described above.

After isolation by ultracentrifugation, lipoproteins were separated by size using gel filtration chromatography on a $1.5 \mathrm{~cm} \times 90-\mathrm{cm}$ column of Bio-Gel A-15m, 200-400 mesh (Bio-Rad Laboratories, Richmond, CA) into region I, II, III, and IV lipoproteins (Fig. 6) (19). The material within these size populations was then pooled and concentrated by dialysis against 40\% Dextran T-500 (Pharmacia Fine Chemicals, Piscataway, NJ), containing 0.01\% EDTA, 0.02\% $\mathrm{NaN}_{3}$, pH 7.2-7.5. For region I, II, and III lipoproteins, samples containing 1-5 mg of cholesterol were adjusted by dialysis to a density of $1.06 \mathrm{~g} / \mathrm{ml}$ in a final volume of $4.0 \mathrm{ml}$. They were then placed in an ultracentrifuge tube for the SW 40 rotor, were overlayered with $3.0 \mathrm{ml}$ each of $\mathrm{KBr}$ solutions with densities of $1.04 \mathrm{~g} / \mathrm{ml}, 1.019 \mathrm{~g} / \mathrm{ml}$, and $1.006 \mathrm{~g} / \mathrm{ml}$, and were centrifuged for $24 \mathrm{~h}$ at $40,000 \mathrm{rpm}, 15^{\circ} \mathrm{C}$, in a Beckman L5-50 ultracentrifuge. For region IV lipoproteins, the sample was adjusted by dialysis to a density of $1.21 \mathrm{~g} /$ $\mathrm{ml}$ in a final volume of $4.0 \mathrm{ml}$ and was overlayered in the ultracentrifuge tube with $3.0 \mathrm{ml}$ each of $\mathrm{KBr}$ solutions with densities of $1.11 \mathrm{~g} / \mathrm{ml}, 1.08 \mathrm{~g} / \mathrm{ml}$, and $1.05 \mathrm{~g} / \mathrm{ml}$. The sample was centrifuged for $40 \mathrm{~h}$ at $40,000 \mathrm{rpm}, 15^{\circ} \mathrm{C}$, in the SW 40 rotor. Gradients were fractionated by piercing the bottom of the tube and pumping in Fluorinert (Instrumentation Specialties Co., Lincoln, NE), forcing the sample out of the top of the tube. Absorbance of the effluent was continuously monitored at $280 \mathrm{~nm}$, and $0.5-\mathrm{ml}$ fractions were collected. Refractive index was determined using an Abbe refractometer (Bausch and Lomb Inc., Rochester, NY), and the density of fractions was determined using standard solutions of known density and refractive index. Fractions within specific density ranges were pooled and dialyzed for further analysis.

Electron microscopy. Livers were fixed by perfusion with $1 \%$ (vol/vol) glutaraldehyde and 3\% (wt/vol) paraformaldehyde in Krebs-Henseleit original Ringer bicarbonate buffer, $\mathrm{pH}$ 7.4. Tissue obtained from different lobes was postfixed in osmium, dehydrated in ethanol and propylene oxide, and embedded in Epon. Thin sections were stained in alkaline lead citrate and uranyl acetate and viewed in a Philips TEM 400 electron microscope (Philips Electronic Instruments, Inc., Mahwah, NJ). Negative stain electron microscopy was performed on perfusate lipoproteins with $2 \%$ (wt)

\footnotetext{
${ }^{1}$ Abbreviations used in this paper: apo A, B, C, apolipoprotein A, B, and C; LCAT, lecithin:cholesterol acyltransferase; SDS-PAGE, sodium dodecyl sulfate-polyacrylamide gel electrophoresis.
}

vol) potassium phosphotungstate, $\mathrm{pH}$ 6.5, on formvar, carbon-coated 200 mesh copper grids. Lipoprotein size was measured with either a sonic digitizer (Science Accessories Corp., Southport, CT) or an ocular micrometer. For each sample, 100-300 particles were measured from photographs at a total magnification of $\times 147,000$.

Lipoprotein radiolabeling. For studies of LDL catabolism by the perfused liver, LDL were isolated by agarosecolumn chromatography (19) from the plasma of test dietfed animals that subsequently served as donors for liver perfusion. LDL were radiolabeled with ${ }^{125} I$ as previously described (20), by the method of McFarlane (21) as modified by Bilheimer et al. (22). Levels of radioactivity in samples were determined with a 1185 series automatic gamma counting system (Searle Analytic Inc., Des Plaines, IL). Specific activity of radiolabled LDL was $500-1,000 \mathrm{cpm} / \mu \mathrm{g}$ of protein, and 3-5\% of the radioactivity was extractable with chloroform/methanol, 2:1 (vol/vol).

Analytical methods. Plasma cholesterol concentration was measured according to the AutoAnalyzer II (Technicon Instruments Corp., Tarrytown, NY) methodology of Rush et al. (23). Plasma apolipoprotein B (apo B) concentration was measured by electroimmunoassay, essentially as described by Rosseneu et al. (24). Lipids were extracted from isolated lipoprotein subfractions with chloroform/methanol, $2: 1$, and lipoprotein cholesterol was measured according to the method of Rudel and Morris (25). Lipid phosphorus was measured according to the method of Fiske and Subbarow (26). Protein was estimated according to Lowry et al. (27), with the modification of Kashyap et al. (28) with bovine serum albumin as the standard. Thin-layer chromatography of lipid extracts was performed on silica gel 60F-254 plates (Brinkmann Instruments, Inc., Westbury, NY), using a solvent system of Skellysolve B/diethyl ether/glacial acetic acid (146:50:4). Separated lipid classes were eluted from the gel according to Skipski and Barclay (29). Triglyceride was measured according to Sardesai and Manning (30). The apoproteins of isolated lipoprotein subfractions were identified by polyacrylamide gel electrophoresis (PAGE) in sodium dodecyl sulfate (SDS). Lipoprotein samples were dialyzed against distilled water containing $0.01 \%$ EDTA, pH 7.4 , and lyophilized. They were then resolubilized in $1 \%$ SDS and apoproteins were separated in a horizontal slab gel as described previously (31). The identity of apoproteins in the samples was determined by comparing their position of migration with that of purified apoproteins from plasma lipoproteins.

Statistical analysis. Values in the text, tables, and figures are expressed as the arithmetic mean \pm SEM. Statistical comparisons were performed using the two-tailed Student's $t$ test.

\section{RESULTS}

Plasma lipoprotein responses to diet. Plasma samples were taken from each animal twice during the 24-60 mo the animals consumed the diets, and the lipoproteins were separated and analyzed. The results are summarized in Table I. The animals consuming the test diet had higher average concentrations of total plasma cholesterol, LDL, and apo B and had higher LDL molecular weights.

Viability of perfused livers. Liver weights averaged $\sim 100 \mathrm{~g}$ and were the same in both control and test diet- 
TABLE I

Effect of Two Different Concentrations of Dietary Cholesterol on Plasma LDL in African Green Monkeys

\begin{tabular}{lrcccr}
\hline $\begin{array}{c}\text { Diet, cholesterol } \\
\text { concentration }\end{array}$ & $n$ & $\begin{array}{c}\text { Plasma } \\
\text { cholesterol }\end{array}$ & Apo B & $\begin{array}{c}\text { L.DL mass } \\
\text { concentrationt }\end{array}$ & $\begin{array}{c}\text { LDI, molecular } \\
\text { weight }\end{array}$ \\
\hline & & $m g / d l$ & $m g / d l$ & $m g / d l$ & $g / \mu m o l$ \\
Control, $0.16 \mathrm{mg} / \mathrm{kcal}$ & 8 & $150 \pm 10$ & $68 \pm 9$ & $166 \pm 20$ & $3.19 \pm 0.09$ \\
Test, $0.78 \mathrm{mg} / \mathrm{kcal}$ & 10 & $278 \S \pm 37$ & $119 \$ \pm 21$ & $489 \$ \pm 106$ & $3.74 \$ \pm 0.10$ \\
\hline
\end{tabular}

All values, mean \pm SEM for two separate analyses on each animal.

- Apoprotein values were measured by electroimmunoassay on seven and eight animals per control and test diet group, respectively.

I LDL mass concentration was calculated as the combined mass concentrations of LDI. protein, phospholipid, free cholesterol, cholesteryl ester, and triglyceride.

$\S$ Statistically significant difference from control diet value, $P<0.01$.

fed animals. The livers remained viable throughout the 5.5-h perfusions, as evaluated by several metabolic and morphologic criteria. Liver color and consistency appeared normal throughout the perfusions. The data in Fig. 1 show that the average rate of bile flow was reasonably constant at $\sim 1 \mathrm{ml} / \mathrm{h}$, and urea accumulated in the perfusate at a steady rate. The rate of oxygen consumption averaged $0.025 \mathrm{ml} / \mathrm{min}$ per $\mathrm{g}$ liver. Portal $\mathrm{PO}_{2}$ was $200-300 \mathrm{mmHg}$, portal $\mathrm{PCO}_{2}$ was $20-30 \mathrm{mmHg}$, and $\mathrm{pH}$ was maintained between 7.2 and 7.4. The extent of hemolysis was below $0.5 \% / \mathrm{h}$ in all perfusions. Livers perfused for up to $6 \mathrm{~h}$ had normal architecture by gross examination and by light microscopy. Electron microscopy revealed generally normal ultrastructure of the hepatocytes (Fig. 2). One exception was the appearance of some open areas of the cytoplasm, suggesting that the cellular water content may have increased during perfusion.

Accumulation of perfusate cholesterol. The rate of accumulation of cholesterol in the perfusate was biphasic in perfusions in which the perfusate was not replaced with fresh medium after $90 \mathrm{~min}$ (Fig. 3). The first 60$90 \mathrm{~min}$ of perfusion was characterized by a more rapid rate of accumulation of perfusate cholesterol, compared with the rate at later times. This early more rapid phase may have been due to the release of preformed lipoproteins bound to hepatocytes and/or trapped within the spaces of Disse (12) in addition to active secretion of lipoproteins. The rate of accumulation of perfusate cholesterol during the later, linear phase was greater from livers of animals fed the test diet, $3.1 \pm 0.3 \mathrm{mg} / \mathrm{h}$ per 100 $\mathrm{g}$ liver, than from livers of animals fed the control diet, $1.2 \pm 0.2 \mathrm{mg} / \mathrm{h}$ per $100 \mathrm{~g}$ liver, $(P<0.005)$. Replacement of the perfusate with fresh medium after $90 \mathrm{~min}$ of recirculation resulted in a monophasic rate of accumulation of cholesterol in the perfusate during the subsequent 4$\mathrm{h}$ period (data not shown). Therefore, in subsequent ex- periments the perfusate was replaced with fresh medium after $90 \mathrm{~min}$, and only lipoproteins accumulating in the perfusate during the succeeding $4 \mathrm{~h}$ were isolated and characterized. The rates of cholesterol accumulation in the perfusates were positively correlated with the animals' plasma cholesterol concentrations $(r=0.92$, Fig. $4 \mathrm{~A})$ as well as with the molecular weights of the animals' plasma LDL $(r=0.82$, Fig. 4 B) obtained from terminal blood samples.

Lipoprotein size and distribution. Agarose-column chromatography elution profiles of plasma and liver perfusate lipoproteins from a representative animal fed the test diet are shown in Fig. $5 \mathrm{~A}$. The plasma lipoproteins consisted mostly of material eluting in region III (LDL)

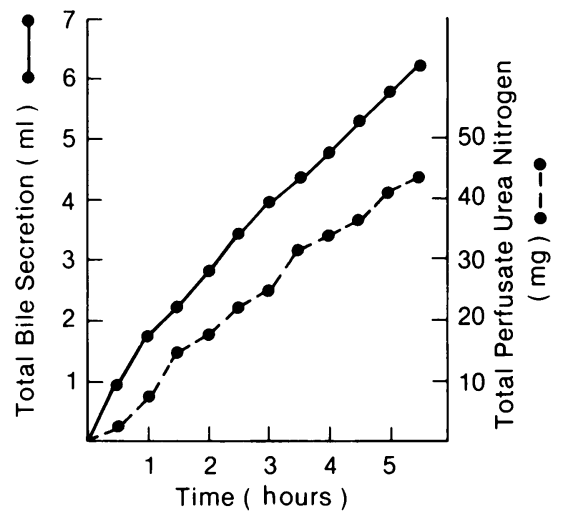

Figure 1 Bile secretion and urea production by perfused liver. Livers were perfused with medium containing $22 \%$ erythrocytes. The perfusate was replaced with fresh medium after $90 \mathrm{~min}$, and perfusion was continued for an additional $4 \mathrm{~h}$. Results presented here are from a representative test diet-fed animal with a $97-\mathrm{g}$ liver. Total bile secretion is the total amount of bile accumulated at the indicated times. Total perfusate urea nitrogen is the total amount of urea nitrogen accumulated in the perfusate at the indicated times. 


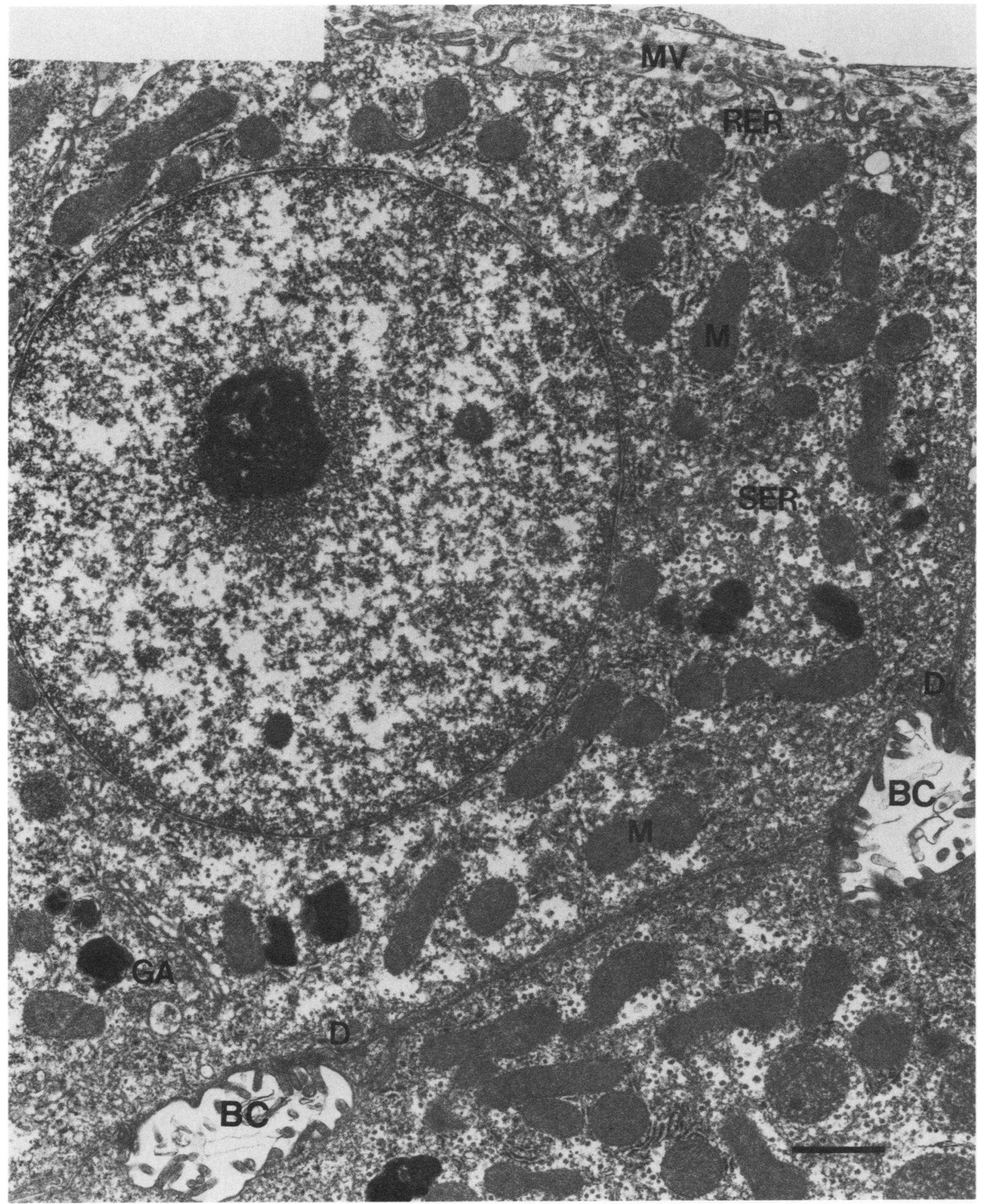

FIGURE 2 Electron micrograph of perfused liver from a test diet-fed monkey after $5.5 \mathrm{~h}$ of perfusion. Normal hepatic architecture is preserved with a fenestrated lining of the sinusoids by endothelial cells, underneath which project well-defined microvilli $(M V)$ of the hepatocytes. Bile canaliculi $(B C)$ are bounded by intact desmosomal junctions $(D)$. A nearby Golgi apparatus $(G A)$ with budding secretory vesicles is evident. Mitochondria $(M)$ are numerous. The nucleus is round and contains a prominent nucleolus. Areas of smooth endoplasmic reticulum (SER) are present containing numerous beta granules of stored glycogen. Sections of undilated rough endoplasmic reticulum $(R E R)$ are scattered throughout the cytoplasm. The bar marker represents $1 \mu \mathrm{m}$. 


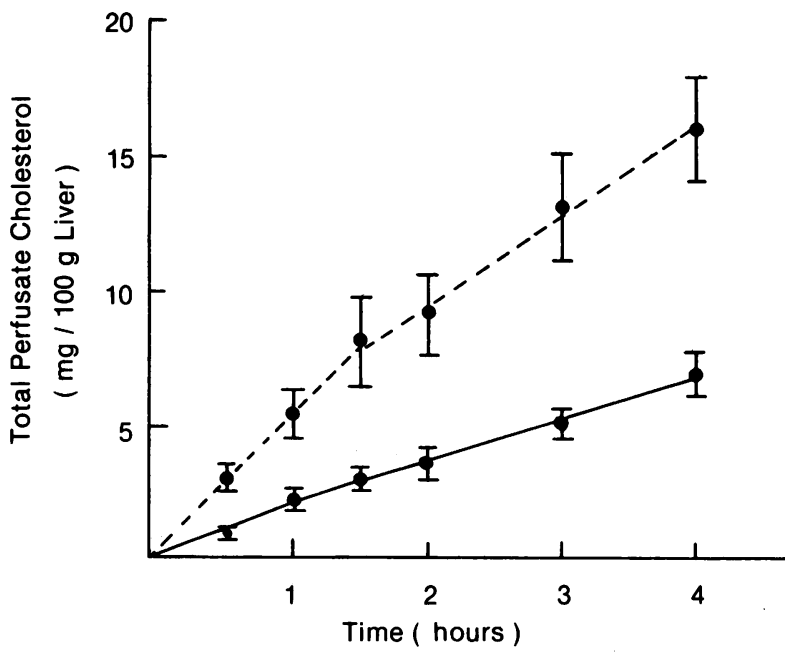

Figure 3 Effect of dietary cholesterol level in the liver donor animals on the rate of accumulation of cholesterol in liver perfusates. Livers were perfused for $4 \mathrm{~h}$ without changing the medium. Total perfusate cholesterol is the total amount of cholesterol accumulated in the perfusate at the indicated times. Values are means $\pm S E M$ for four control diet-fed animals $(-\bullet)$ and seven test diet-fed animals (0 - - normalized for $100-\mathrm{g}$ liver.

and region IV (HDL). In contrast, liver perfusate lipoproteins consisted mostly of a wide spectrum of much larger particles eluting primarily in regions I and II, with somewhat less material of HDL-size eluting in region IV. Only small amounts of perfusate material eluted in region III, corresponding to the region in which plasma LDL were eluted. The elution profiles of perfusate lipoproteins isolated from animals on the control diet were generally similar to those of perfusate lipoproteins from animals on the test diet. No differences were detected in the elution profiles of perfusate lipoproteins accumulated during $2 \mathrm{~h}$ of perfusion, compared with those accumulated during $4 \mathrm{~h}$ of perfusion (data not shown).

The elution profiles of liver perfusate lipoproteins from another test diet-fed animal are shown in Fig. $5 B$. In this case, perfusate $d<1.006 \mathrm{~g} / \mathrm{ml}$ lipoproteins (VLDL) and $1.006<d<1.225 \mathrm{~g} / \mathrm{ml}$ lipoproteins were separated by ultracentrifugation before column chromatography. Perfusate VLDL eluted in regions I, II, and III. Negative stain electron microscopy of unfractionated perfusate VLDL also revealed that this lipoprotein class was a heterogeneous population of particles $(250-600 \AA$ in diameter, Fig. 6 A). A considerable amount of material from perfusate lipoproteins $1.006<d<1.225 \mathrm{~g} / \mathrm{ml}$ eluted in regions I, II, and III and in region IV. Region I consisted of irregularly shaped particles that appeared to be membranous or vesicular in structure (Fig. $6 \mathrm{~B}$ ). Region II consisted

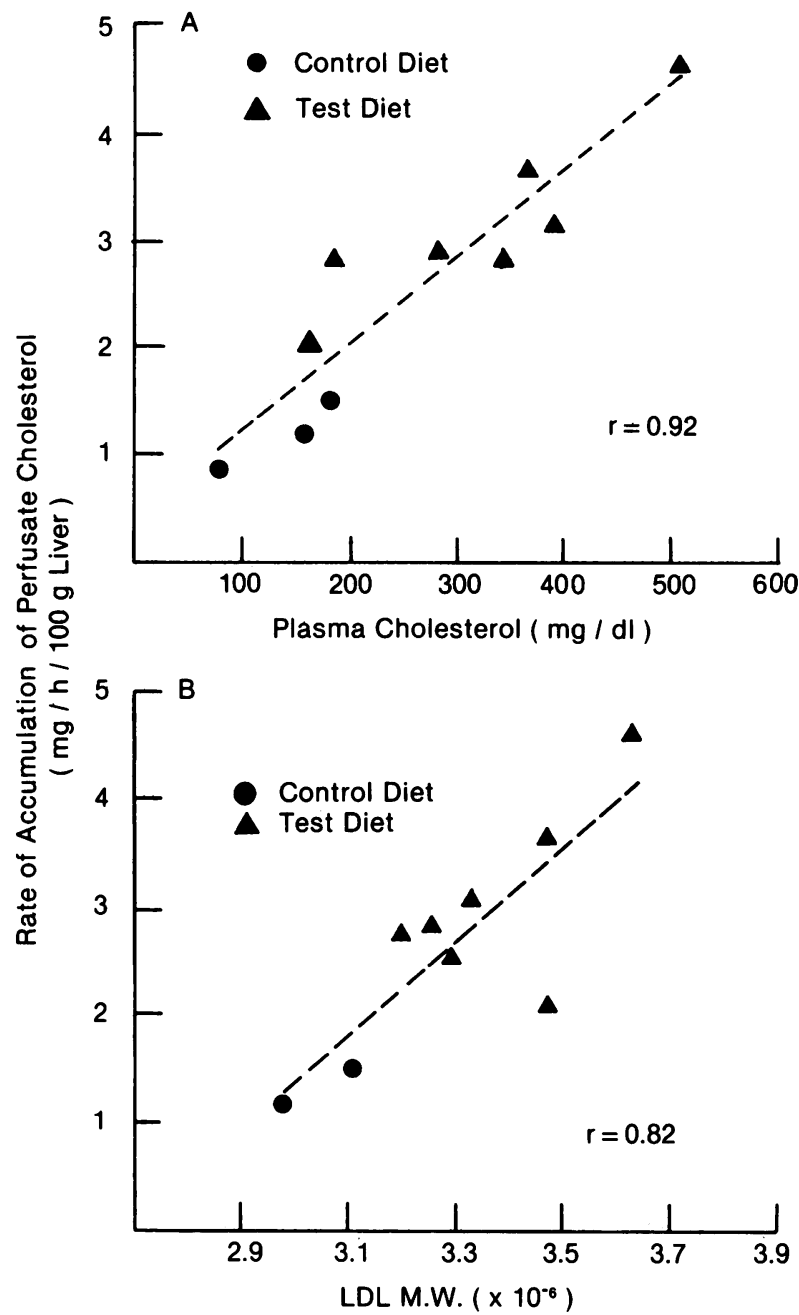

Figure 4 Relationship of plasma cholesterol level and LDL molecular weight (M.W.) in the liver donor animals to the rate of accumulation of cholesterol in liver perfusates. Livers were perfused for 4 or $5.5 \mathrm{~h}$. Perfusate cholesterol accumulation rate was calculated as the slope of the least-squares regression of values measured during the final linear portion of the curve. Plasma cholesterol concentration $(A)$ and LDL molecular weight $(B)$ were determined on the blood sample taken at the time of the liver perfusion or on the latest blood sample taken during the experimental diet-feeding period.

of 250-500 $\AA$ particles that sometimes appeared to be partly empty or to carry excess surface material (Fig. $6 \mathrm{C}$ ). Some appeared to be completely empty or flat. Region III appeared to be similar in structure to region II lipoproteins except for the smaller size of the particles $(200-250 \AA$ in diameter, Fig. $6 D$ ). The material that eluted in this region was frequently pooled with that in region II for further analysis. Perfusate lipoproteins that eluted in region IV appeared to consist 


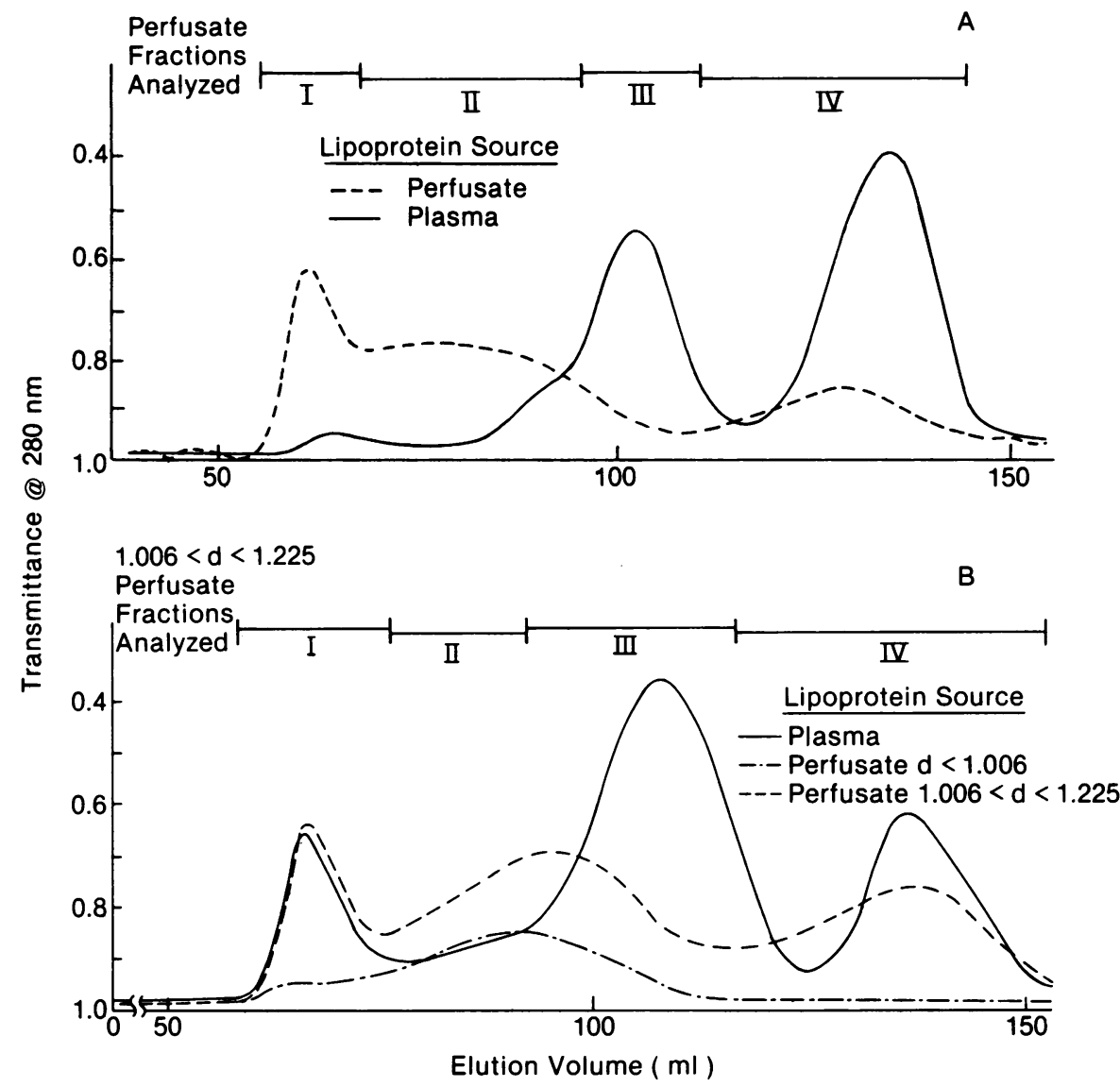

Figure 5 Agarose-column chromatography elution profiles of liver perfusate and plasma lipoproteins from two representative test diet-fed animals. (A) The liver was perfused for a 90min period, followed by a 4-h period (Methods). All lipoproteins were isolated together by ultracentrifugal flotation at $d 1.225 \mathrm{~g} / \mathrm{ml}$ from the perfusate after the 4 -h period of perfusion and from the plasma of the liver donor. Lipoproteins were then separated on a $1.5 \times 90 \mathrm{~cm}$ column of $4 \%$ agarose (Bio Gel A-15m, Bio-Rad Laboratories), as previously described (17). Fractions within the regions indicated by the Roman numerals were pooled for subsequent analysis. (B) The liver was perfused as in panel $A$. VLDL were isolated by ultracentrifugation at $d<1.006 \mathrm{~g} / \mathrm{ml}$, followed by isolation of the remaining lipoproteins at $1.006<d<1.225$ $\mathrm{g} / \mathrm{ml}$. Lipoproteins were then fractionated by column chromatography as in panel $A$.

of at least two morphologically distinct types. One type appeared as discoidal particles with average dimensions of $165 \pm 4$ by $44 \pm 0.4 \AA$, which tended to form rouleaux upon negative staining (Fig. $6 \mathrm{E}$ ). Another type appeared as round, free-standing particles that were $108 \pm 3 \AA$ in diameter.

Table II shows the distribution of cholesterol among the different perfusate lipoprotein fractions. VLDL represents lipoproteins initially isolated from the perfusate at $d<1.006 \mathrm{~g} / \mathrm{ml}$. The other lipoproteins were isolated from perfusate at $1.006<d<1.225 \mathrm{~g} / \mathrm{ml}$ and fractionated by agarose-column chromatography. No consistent differences in the percentage distribution of cholesterol among perfusate lipoproteins were found between animals on control and test diets.

Subfractionation of perfusate lipoproteins in density gradients. Perfusate $1.006<d<1.225 \mathrm{~g} / \mathrm{ml}$ lipoprotein fractions separated by agarose-column chromatography were further subfractionated by density gradient ultracentrifugation (Fig. 7). About 85\% of the cholesterol in the perfusate region I lipoproteins was recovered between the densities of 1.02 and 1.065 $\mathrm{g} / \mathrm{ml}(\mathrm{Fig} .7 \mathrm{~A}$ ). About $65 \%$ of the cholesterol in lipoproteins from regions II and III was present in the $1.02<d<1.065 \mathrm{~g} / \mathrm{ml}$ interval and $30 \%$ was in the $1.006<d<1.02 \mathrm{~g} / \mathrm{ml}$ interval (Fig. $7 \mathrm{~B}$ ). In region 

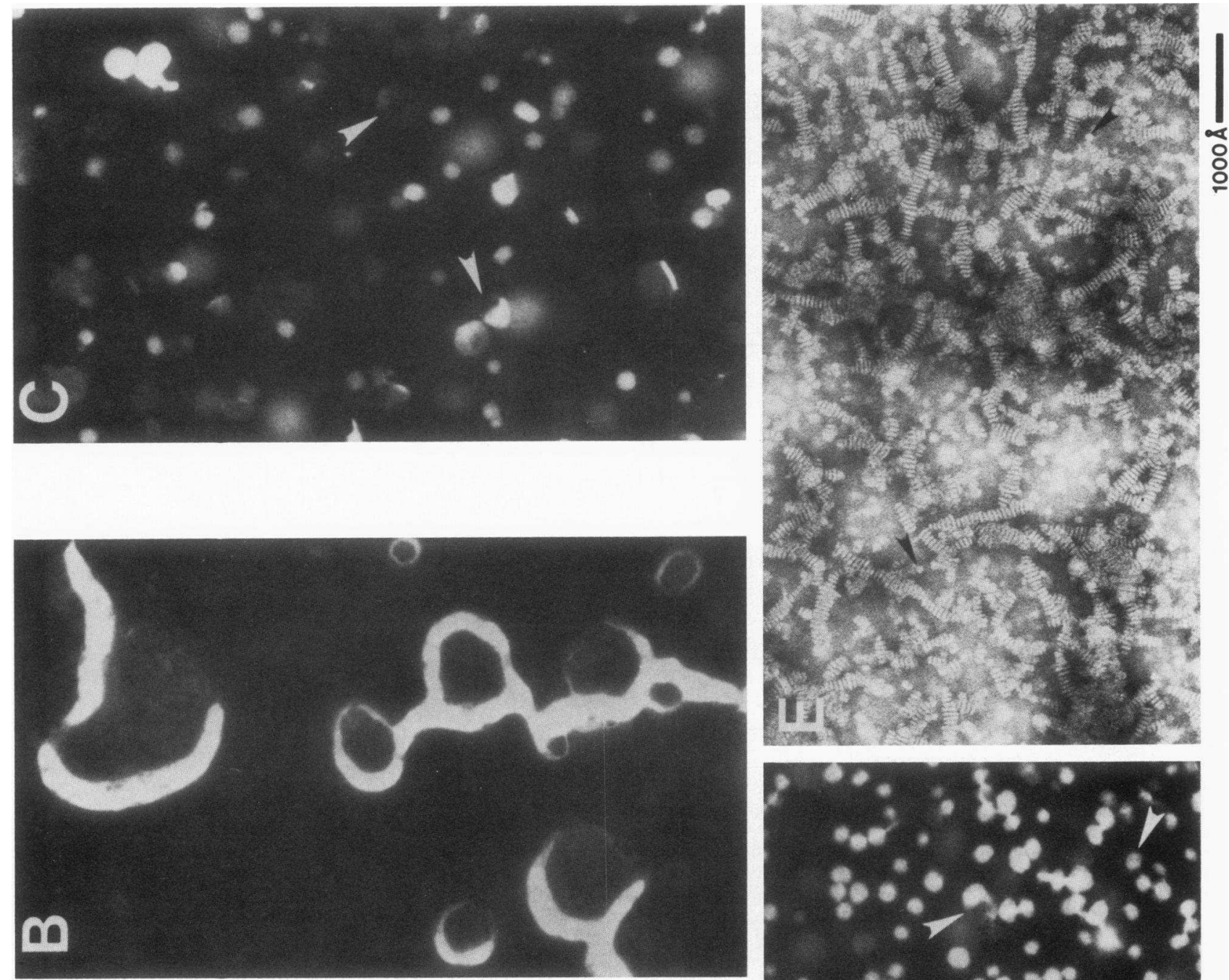

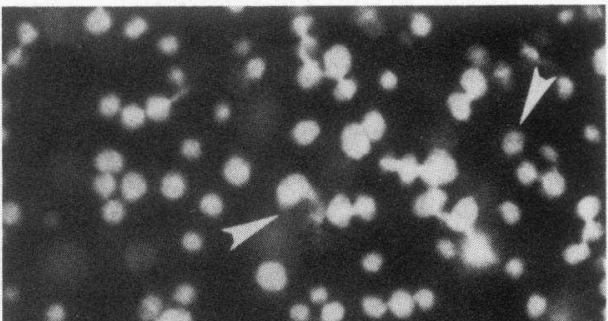

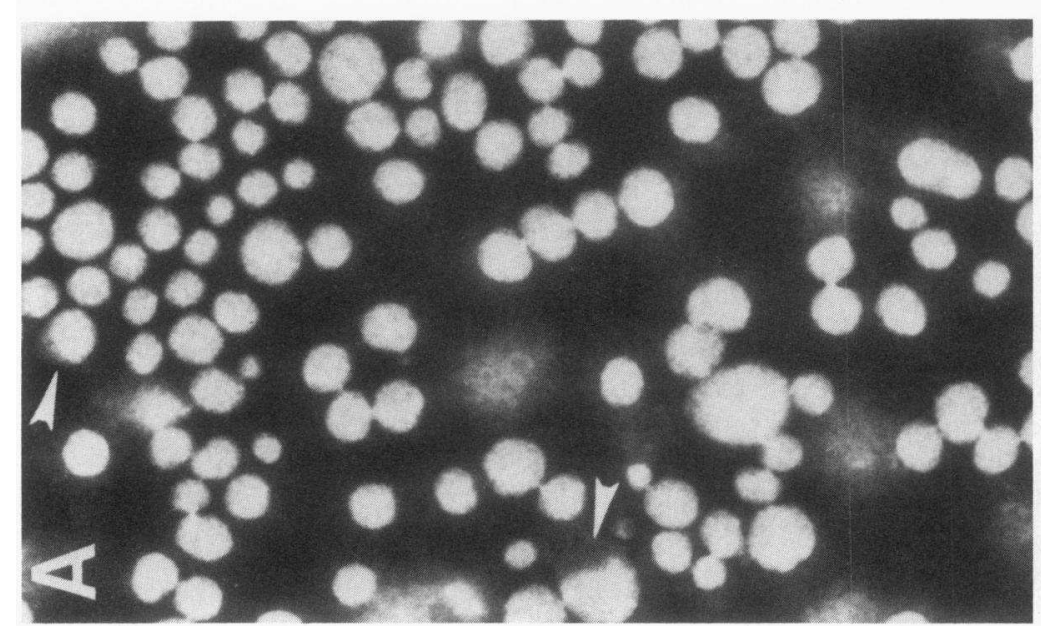

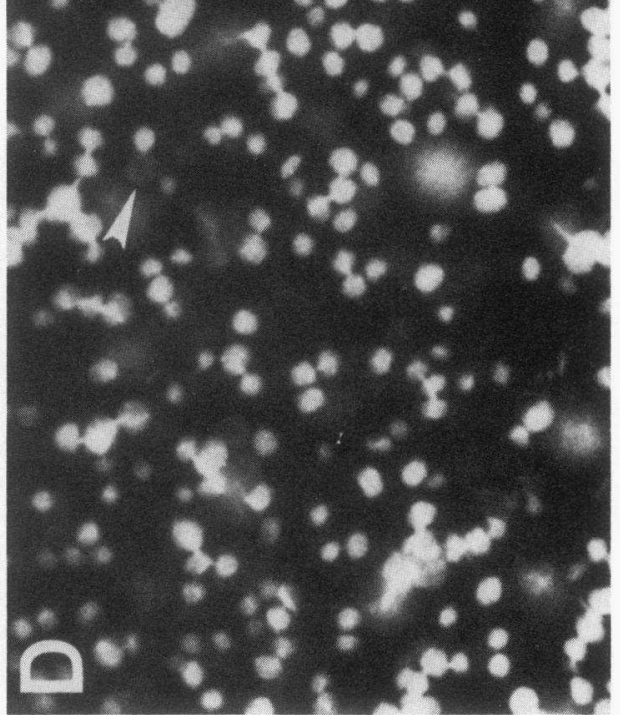


TABLE II

Cholesterol Distribution among Liver Perfusate Lipoproteins

\begin{tabular}{lccccc}
\hline Diet group & $n$ & VLDL. & It & II + III & IV \\
\hline & & & $\%$ & \\
Control & 4 & $29 \pm 3.6$ & $15 \pm 2.7$ & $41 \pm 3.9$ & $16 \pm 1.8$ \\
Test & 5 & $34 \pm 7.0$ & $17 \pm 4.5$ & $35 \pm 4.6$ & $15 \pm 2.0$ \\
\hline
\end{tabular}

All values are means \pm SEM of the percentage of total perfusate cholesterol contained in each fraction.

- VLDL represents lipoproteins isolated from liver perfusates by ultracentrifugal flotation at $d 1.006 \mathrm{~g} / \mathrm{ml}$.

† Fractions I, II + III, and IV represent lipoproteins isolated from liver perfusates by ultracentrifugal flotation at $1.006<d<1.225$ $\mathrm{g} / \mathrm{ml}$ and separated by column chromatography. Column regions are designated by Roman numerals and correspond to those indicated in Fig. 5.

IV lipoproteins (Fig. $7 \mathrm{C}$ ), 35, 40, and $20 \%$ of the cholesterol was contained in the density regions of $d$ $<1.07 \mathrm{~g} / \mathrm{ml}, 1.07<d<1.11 \mathrm{~g} / \mathrm{ml}$, and $1.11<d$ $<1.21 \mathrm{~g} / \mathrm{ml}$, respectively. No consistent diet-related differences were detected in the percentage distribution of cholesterol among the density subfractions.

Composition of perfusate lipoproteins. Table III shows the effects of the test diet on the percentage composition and the rates of accumulation in the perfusate of the major lipoprotein subfractions secreted by perfused livers. Liver perfusates of test diet-fed animals accumulated 5-10 times as much cholesteryl ester in subfractions of $d<1.063$ lipoproteins as did liver perfusates of control diet-fed animals. This elevation in rate of cholesteryl ester accumulation was much greater than the elevations in the rates of accumulation of the other components, indicating that the test diet caused an increased pecentage of cholesteryl ester in these lipoprotein particles (Table III). Perfusate lipoproteins generally were rich in polar lip- ids with relatively small amounts of neutral lipids compared with plasma lipoproteins, a finding consistent with the morphology shown in Fig. 6.

Perfusate subfractions designated $\mathrm{IV}_{1.07-1.11}$ and $\mathrm{IV}_{1.11-1.21}$ were predominantly phospholipid and protein, with only small amounts of cholesteryl ester. No consistent differences in the percentage composition of these subfractions were observed between control and test diet-fed animals. The compositions of these subf ractions are consistent with the abundance of discoidal particles observed in column region IV by electron microscopy (Fig. $6 \mathrm{E}$ ). These were the only lipoproteins isolated from liver perfusates of test dietfed animals that were not enriched in cholesteryl ester, compared with the same subfractions from control diet-fed animals, although perfusates of test diet-fed animals accumulated moderately higher amounts of these subfractions compared with perfusates of control diet-fed animals.

SDS-PAGE. The apoproteins of the major perfusate lipoprotein subfractions were identified using SDSPAGE (Fig. 8). The apoproteins of perfusate VLDL from animals on either the control or test diet were primarily apo $B$ and apo $C$ along with small amounts of apo A-I and apo E (Fig. $8 \mathrm{~A}$ ). Perfusate subfractions from region I, II, and III from both control and test diet-fed animals contained primarily apo $\mathrm{B}$ (Fig. 8 B). Some apo $E$ was detected in the region II + III subfractions. In the HDL subfractions, $\mathrm{IV}_{1.07-1.11}$ and $\mathrm{IV}_{1.11-1.21}$ apo A-I was the predominant apoprotein; bands in the region of apo A-II and apo $\mathrm{C}$ were also present (Fig. $8 \mathrm{~B})$. Apo $\mathrm{E}$ was another major component of subfraction $\mathrm{IV}_{1.07-1.11}$. The HDL subfractions from test dietfed animals, especially $I_{1.07-1.11}$, were consistently enriched in apo $E$, compared with the same subfractions from control diet-fed animals. Apo B was not detected in perfusate HDL from either control or test diet-fed animals.

Figure 6 Negative-stain electron micrographs of liver perfusate lipoproteins. Perfusate VLDL and $1.006<d<1.225 \mathrm{~g} / \mathrm{ml}$ lipoproteins were isolated as shown in Fig. $5 \mathrm{~B}$. The particles shown here are from the perfusate of the liver of a test diet-fed animal. (A) VLDL (before agarose-column chromatography) is a heterogeneous population of generally round particles, 250-600 $\AA$ in diameter, though some particles are easily deformed and show evidence of having excess surface material (arrows). (B) The $1.006<d<1.225 \mathrm{~g} / \mathrm{ml}$ lipoproteins from column region I are very large, amorphous particles of which $>95 \%$ are $>500 \AA$ in diameter. They appear to be membranous or vesicular in nature, as judged by the inclusion of stain within their interiors. $(C)$ The $1.006<d<1.225 \mathrm{~g} / \mathrm{ml}$ lipoproteins from column region II are heterogeneous in structure. Many appear as electron lucent, round particles, but particles often appear partly empty, with flat regions of what appears to be excess surface material (arrows). (D) The $1.006<d<1.225 \mathrm{~g} / \mathrm{ml}$ lipoproteins from column region III consist of round particles, 200-250 $\AA$ in diameter, but also include particles with excess surface material (arrows). Discoidal particles similar to those in panel $E$ were occasionally seen. $(E)$ The $1.006<d<1.225$ $\mathrm{g} / \mathrm{ml}$ lipoproteins from column region IV were predominantly discoidal particles, $165 \times 44 \AA$, which tended to form rouleaux. Some round, free-standing particles, 70-150 $\AA$ in diameter, were also seen (arrows). 


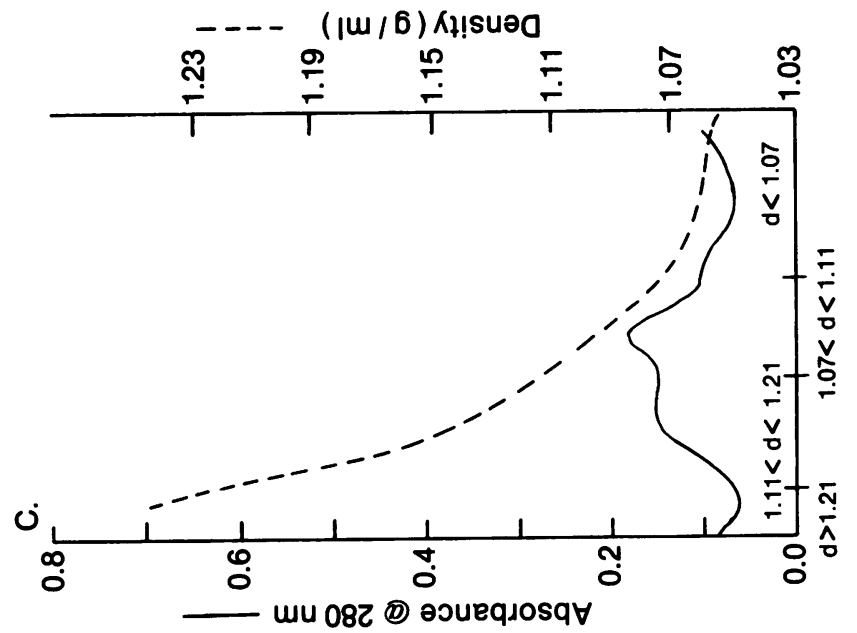

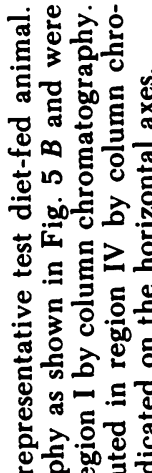

ก

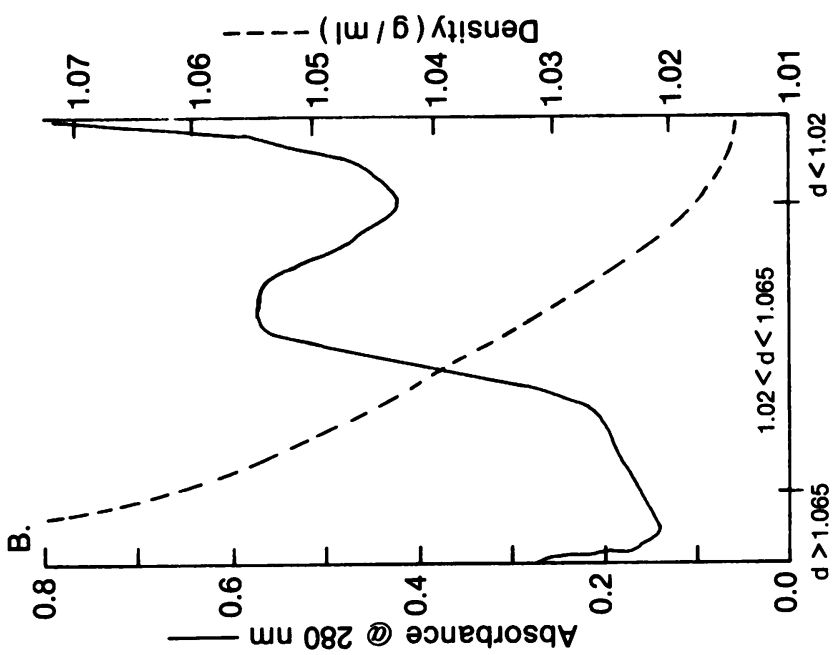

후워

응형ㅇㅇㅇ

元它这

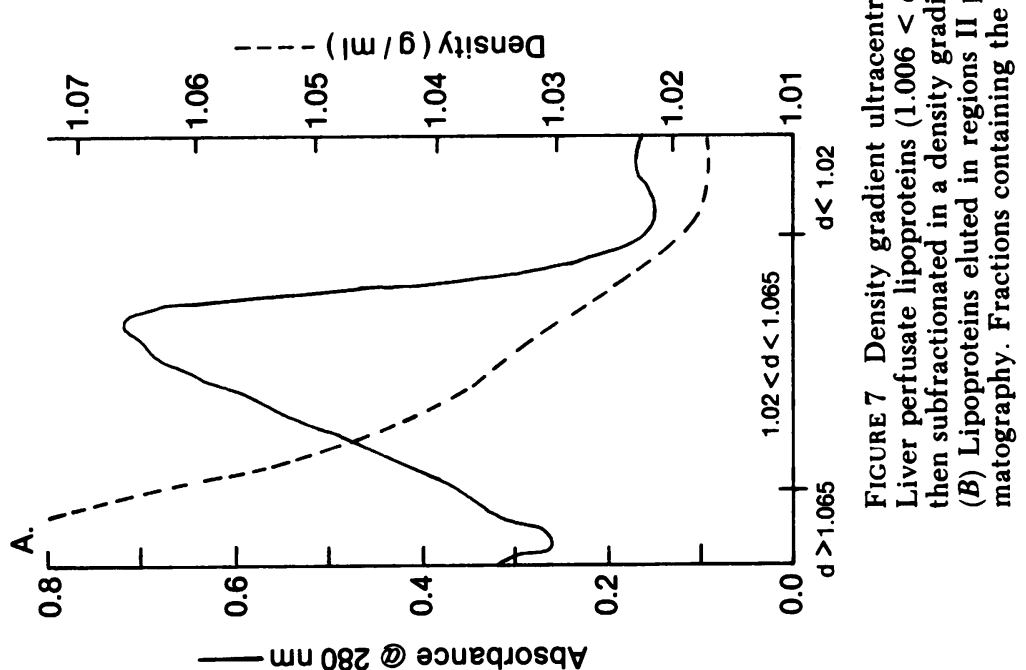


TABLE III

Effects of Dietary Cholesterol on Liver Perfusate Lipoprotein Secretion Rates and Composition

\begin{tabular}{|c|c|c|c|c|c|c|c|}
\hline & & & \multicolumn{5}{|c|}{$\mu \mathrm{g} / \mathrm{h} / 100 \mathrm{~g}$ liver (\% mass) } \\
\hline \multirow[t]{2}{*}{ VLDL• } & Control & $\begin{array}{c}3 \\
(4) \downarrow\end{array}$ & $\begin{array}{c}602 \pm 39 \\
(12)\end{array}$ & $\begin{array}{c}1190 \pm 73 \\
(25)\end{array}$ & $\begin{array}{c}262 \pm 26 \\
(5.6)\end{array}$ & $\begin{array}{c}2390 \pm 94 \\
(54)\end{array}$ & $\begin{array}{r}183 \pm 41 \\
(3.6)\end{array}$ \\
\hline & Test & $\begin{array}{c}5 \\
(6)\end{array}$ & $\begin{array}{c}580 \pm 214 \\
(10)\end{array}$ & $\begin{array}{c}1830 \pm 417 \\
(23)\end{array}$ & $\begin{array}{c}460 \pm 110 \\
(6.2)\end{array}$ & $\begin{array}{c}3820 \pm 926 \\
(48)\end{array}$ & $\begin{array}{c}908 \pm 132 \\
(13)\end{array}$ \\
\hline \multirow[t]{2}{*}{$I_{1.02-1.065} \S$} & Control & $\begin{array}{c}2 \\
(2)\end{array}$ & $\begin{array}{c}87 \\
(8.1)\end{array}$ & $\begin{array}{l}744 \\
(69)\end{array}$ & $\begin{array}{l}190 \\
(18)\end{array}$ & $\begin{array}{c}56 \\
(4.7)\end{array}$ & $\begin{array}{c}16 \\
(1.4)\end{array}$ \\
\hline & Test & $\begin{array}{c}5 \\
(6)\end{array}$ & $\begin{array}{c}182 \pm 76 \\
(12)\end{array}$ & $\begin{array}{c}600 \pm 15 \\
(48)\end{array}$ & $\begin{array}{c}206 \pm 56 \\
(18)\end{array}$ & $\begin{array}{c}192 \pm 59 \\
(13)\end{array}$ & $\begin{array}{c}170 \pm 86 \\
(9.5)\end{array}$ \\
\hline \multirow[t]{2}{*}{$I I+I I I I_{1.02-1.065} \S$} & Control & $\begin{array}{c}2 \\
(2)\end{array}$ & $\begin{array}{l}277 \\
(16)\end{array}$ & $\begin{array}{c}1,000 \\
(54)\end{array}$ & $\begin{array}{l}261 \\
(14)\end{array}$ & $\begin{array}{l}183 \\
(14)\end{array}$ & $\begin{array}{c}47 \\
(2.8)\end{array}$ \\
\hline & Test & $\begin{array}{c}4 \\
(6)\end{array}$ & $\begin{array}{c}606 \pm 122 \\
(14)\end{array}$ & $\begin{array}{c}1,730 \pm 180 \\
(47)\end{array}$ & $\begin{array}{c}467 \pm 90 \\
(12)\end{array}$ & $\begin{array}{l}554 \pm 122 \\
(15)\end{array}$ & $\begin{array}{c}731 \pm 364 \\
(12)\end{array}$ \\
\hline $\mathrm{IV}_{1.07-1.11} \S$ & Control & $\begin{array}{c}2 \\
(2)\end{array}$ & $\begin{array}{l}274 \\
(28)\end{array}$ & $\begin{array}{l}552 \\
(54)\end{array}$ & $\begin{array}{c}98 \\
(9.4)\end{array}$ & $\begin{array}{c}53 \\
(6.4)\end{array}$ & $\begin{array}{c}27 \\
(3.0)\end{array}$ \\
\hline
\end{tabular}

Pr, protein; PL, phospholipid; FC, free cholesterol; TG, triacylglycerol; CE, cholesteryl esters = esterified cholesterol $\times 1.7 ; n$, number of livers.

- VLDL were isolated from the perfusate by ultracentrifugation at $d<1.006 \mathrm{~g} / \mathrm{ml}$.

I Values in parentheses are the number of samples analyzed for percentage composition and the mean percentage values.

\$ Perfusate lipoproteins of $1.006<d<1.225 \mathrm{~g} / \mathrm{ml}$ were separated by agarose-column chromatography and subfractionated by density gradient ultracentrifugation. Roman numerals designate the region of elution from the column, and subscripts designate the ranges of densities within which each subfraction was isolated.

The different molecular weight forms of apo B were separated in $5 \%$ polyacrylamide gels (Fig. $8 \mathrm{C}$ ). In all of the perfusate subfractions examined, from both control and test diet-fed animals, only the larger molecular weight form of apo B, labeled Bl, was present, as indicated by the co-migration with the apo $\mathrm{B}$ of plasma LDL. The position in the gel of the smaller form of apo B, labeled B2, is shown by including a sample of thoracic lymph duct chylomicra in well 7 of Fig. $8 \mathrm{C}$. Catabolism of radioiodinated $L D L$. Since only a small amount of LDL-size particles were found in liver perfusates, the question arose whether LDL was being catabolized during recirculation subsequent to secretion by the perfused liver. This possibility was 
A

B
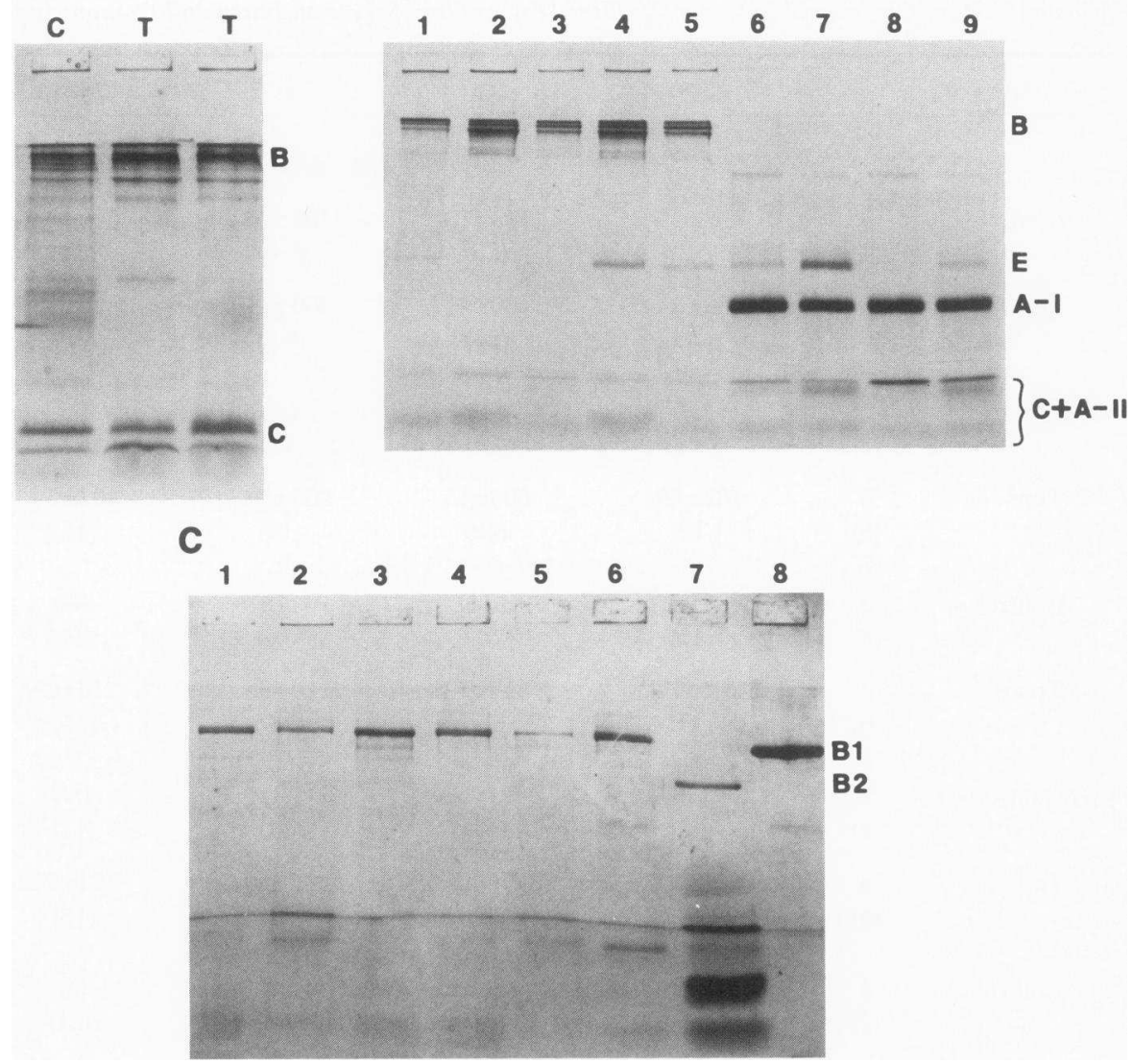

FIGURE 8 SDS-PAGE of liver perfusate lipoproteins. Liver perfusate lipoproteins were electrophoresed in either $12 \%(A$ and $B$ ) or $5 \%(C)$ polyacrylamide slab gels containing $0.1 \%$ SDS. Gels were fixed and stained with Coomassie Brilliant Blue R-250. Letter designations for the apoproteins are on the right of each panel. $(A)$ Liver perfusate VLDL from one control $(C)$ and two test diet-fed animals $(T)$. (B) Liver perfusate lipoproteins from one control and one test diet-fed animal. Lane 1 , test, $\mathrm{I}_{1.02-1.065}$; lane 2 , control, II $+\mathrm{III}_{1.006-1.02}$; lane 3 , test, II $+\mathrm{III}_{1.006-1.02}$; lane 4, control, II + $\mathrm{III}_{1.02-1.065}$; lane 5 , test, II + $\mathrm{III}_{1.02-1.065}$; lane 6 , control, $\mathrm{IV}_{1.07-1.11}$; lane 7, test, $\mathrm{IV}_{1.07-1.11}$; lane 8, control, $\mathrm{IV}_{1.11-1.21}$; lane 9, test, IV $\mathrm{V}_{1.11-1.21}$. (C) Liver perfusate lipoproteins from one control and one test diet-fed animal. Lane 1, test, VLDL; lane 2 , test, $\mathrm{I}_{1.02-1.065}$; lane 3 , control, II $+\mathrm{III}_{1.006-1.02}$; lane 4 , test, II $+\mathrm{III}_{1.006-1.02}$; lane 5 , control, II + III $I_{1.02-1.065}$; lane 6 , test, II + III $1.02-1.065$; lane 7 , thoracic lymph duct chylomicra; lane 8 , plasma LDL.

tested by including in the perfusate trace amounts of radioiodinated LDL that had been obtained from the plasma of the liver donor monkey. Total trichloroacetic acid (TCA) soluble ${ }^{125}$ I-radioactivity increased linearly throughout the perfusion, but accounted for an average of only $6 \%$ of the injected dose after $4 \mathrm{~h}$ (Fig. 9). Most of this ${ }^{125}$ I was free iodide (extractable with chloroform after oxidation with hydrogen peroxide) and much lower concentrations of TCA soluble, noniodide ${ }^{125}$ I-labeled material were found (Fig. 9). The free iodide was apparently due in large part to the activity of deiodinase in the perfusate (unpublished observations). Therefore, the amount of LDL protein catabolized during $4 \mathrm{~h}$ of perfusion was minimal, i.e., $<6 \%$ of the injected dose.

\section{DISCUSSION}

The present studies were designed to test the hypothesis that large molecular weight LDL were secreted directly by the liver in cholesterol-fed African green monkeys. A small portion of the liver perfusate lipoproteins was indeed found to be the same size (200$250 \AA$ ) and to have a similar density as plasma LDL $(1.02-1.06 \mathrm{~g} / \mathrm{ml})$. However, these lipoproteins were 


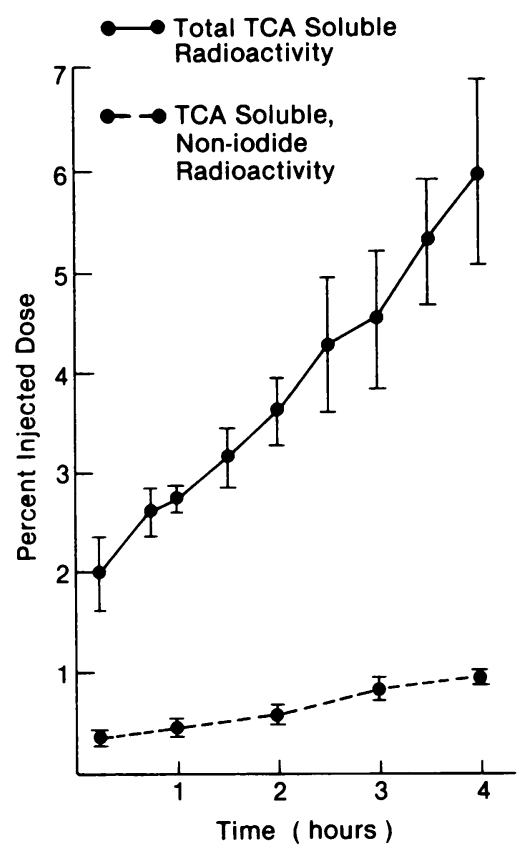

Figure 9 Catabolism of ${ }^{125}$ I-LDL by the perfused liver. LDL were isolated and radiolabeled with ${ }^{125} \mathrm{I}$ as described in Methods. Radiolabeled LDL containing 30-150 ng protein were injected into the perfusate of the liver from the LDL donor monkey. Perfusate samples were measured for total ${ }^{125}$ I radioactivity that was soluble in $10 \%$ TCA over the subsequent $4 \mathrm{~h}$ of perfusion. Iodide in the TCA supernate was oxidized with $\mathrm{H}_{2} \mathrm{O}_{2}$ and extracted with chloroform to determine TCA-soluble, noniodide radioactivity. Values are expressed as the percentage of injected dose and are the means \pm SEM of three experiments.

part of a population of much larger lipoproteins that were relatively poor in cholesteryl ester, whereas plasma LDL are typically $45-50 \%$ by mass cholesteryl ester (1). The failure to isolate a distinct population of plasma LDL-like particles in the perfusate could not be attributed to rapid uptake of newly secreted LDL particles, because minimal amounts of LDL were catabolized during perfusion (Fig. 9). Free fatty acids, known to stimulate the synthesis and secretion of triglyceride by the liver, were not included in the perfusion medium in our studies. Consequently, the availability of free fatty acids to the liver was probably lower than normal. However, this would be expected to result in the secretion of relatively triglyceride-poor particles, more like plasma LDL in composition, rather than to make their presence in the perfusate less likely. These results have led us to reject our hypothesis that large LDL are secreted directly by the liver in nonhuman primates; rather, it appears that the lipoproteins secreted by the liver are more likely immature precursors to mature plasma LDL.
The question then becomes which of the various lipoproteins secreted by the liver are precursors to plasma LDL. This question was not addressed directly by these studies but our data combined with those in the literature allow us to speculate. Several studies in rats (5) and man (6) have shown that plasma VLDL are precursors to plasma LDL. However, it remains to be established what portion of the plasma LDL are derived from plasma VLDL. Indeed, one study in rats (9) indicates that only a small portion of the apo B of plasma LDL appears to be derived from apo $B$ of plasma VLDL, and studies in cynomolgus monkeys suggest that a similar situation exists in this primate (32). It is possible that newly secreted hepatic lipoproteins such as we have isolated are rapidly converted to LDL and do not normally accumulate in the plasma to a significant degree. Such a hypothesis implies that there is a rapidly turning over plasma pool of LDLprecursor, presumably triglyceride-rich lipoproteins, that is metabolically distinguishable from the plasma VLDL. In this regard, Illingworth (10) has provided evidence that the low levels of plasma VLDL in squirrel monkeys is in part due to the high catabolic rate and rapid turnover of VLDL. Furthermore, Illingworth's studies in squirrel monkeys suggested that LDL are derived from particles other than VLDL. We suspect that this is also true for other species of nonhuman primates, including the African green monkey of these studies.

A significant hepatic secretion of the $d$ 1.006-1.063 $\mathrm{g} / \mathrm{ml}$ precursor lipoproteins as we have observed here may provide an explanation for Illingworth's findings. That a variety of hepatic lipoproteins may give rise to plasma LDL is an attractive hypothesis, for it may explain the polydispersity of plasma LDL described in both human beings (33-35) and in several species on nonhuman primates $(1,20,36)$. It would allow for the production of LDL containing different amounts of cholesteryl ester depending, at least in part, on the amount of cholesteryl ester secreted with the LDLprecursor particles. In animals consuming dietary cholesterol, hepatic lipoproteins enriched in cholesteryl ester might be expected to give rise to LDL containing increased amounts of cholesteryl ester, assuming that intravascular metabolism and lipid transfer remains normal. In this case, hepatic secretion of cholesteryl ester may be responsible for the increased cholesteryl ester content and increased size of the plasma LDL seen in cholesterol-fed monkeys. This is consistent with our observations of a strong correlation between the rate of accumulation of perfusate cholesterol and the molecular weight of the donor animal's plasma LDL (Fig. 4 B).

In support of this hypothesis, several types of evidence suggest that the cholesteryl esters of the per- 
fusate lipoproteins are of hepatic origin and are not a product of the action of LCAT in the perfusate. The abundance in the perfusates of discoidal HDL containing only small amounts of cholesteryl ester suggests that LCAT is either absent or inactive in the perfusion system. These particles are similar in structure and composition to the so-called nascent HDL found in perfusates of rat liver in which LCAT is inhibited (37) and to the discoidal plasma HDL from patients with familial LCAT deficiency $(37,38)$. Virtually all of the perfusate lipoproteins from both control and test dietfed animals were enriched in LCAT substrate lipids, as has been described in LCAT-deficient patients (39). Two perfusate lipoprotein subfractions. $I_{1.02-1.065}$ and II + III $_{1.02-1.065}$ were especially rich in phospholipid and unesterified cholesterol. These lipoproteins appeared partly empty or vesicular in structure by electron microscopy, resembling the plasma LDL subfractions from patients with familial LCAT deficiency (40). All these data suggest that LCAT is absent or inactive in the perfusates from both control and test diet-fed animals. Therefore, the differences observed in the rate of accumulation of cholesterol in the perfusates are primarily due to differences in the hepatic secretion rate of cholesteryl esters (Table III).

The increase in size of plasma LDL in cholesterolfed monkeys has been shown to be primarily due to an increased number of cholesteryl oleate and cholesteryl palmitate molecules per LDL particle $(2,41)$. Thus, the cholesteryl esters that increase in number in large molecular weight LDL are more likely to have been formed by acyl-CoA cholesteryl $O$-acyltransferase than by LCAT $(42,43)$. Preliminary results have shown that perfusate lipoprotein cholesteryl esters are rich in cholesteryl oleate and cholesteryl palmitate. ${ }^{2}$ This supports our hypothesis that increased hepatic secretion of cholesteryl ester leads to the increased size of plasma LDL.

The only form of apo B that was detected on the perfusate lipoproteins including the VLDL was the large molecular weight form, apo $B_{100}$, termed apo B1 in Fig. 8. Sparks and Marsh (44) have provided evidence that in rats, the large molecular weight form of apo B on serum triglyceride-rich lipoproteins preferentially becomes associated with plasma LDL, whereas the lower molecular weight form is rapidly catabolized by the liver. We have found that plasma LDL in monkeys contain primarily apo B-1, whereas intestinally derived chylomicra contain predominantly the smaller apo B-2 or apo $\mathrm{B}_{48}(45)$.

Since the perfusion medium was continuously re-

\footnotetext{
${ }^{2}$ Carroll, R. M., F. L. Johnson, and L. L. Rudel. Unpublished observations.
}

circulated through the liver in these studies, the possibility exists that some secreted lipoproteins did not accumulate in the perfusate because of subsequent modification or catabolism by the liver during perfusion. However, such changes would not appear to obviate our conclusion that the cholesteryl ester enrichment of perfusate lipoproteins from test diet-fed animals was due to hepatic secretion of cholesteryl esters in lipoproteins. We isolated the lipoprotein from the perfusates of livers from butter-fed animals at $4^{\circ} \mathrm{C}$. Others have shown that low temperatures can induce crystallization of lipids and unusual lipoprotein structures as visualized by electron microscopy (46). To rule this out as the explanation for some of the structures shown in Fig. 6, we perfused the livers from animals fed safflower oil, in which the predominant adipose tissue, liver, and plasma triglyceride and cholesteryl ester fatty acid is linoleic acid. Triglyceride-rich lipoproteins from these animals have transition temperatures below $4^{\circ} \mathrm{C}(47)$. The same structures as shown in Fig. 6 have been found in each of the lipoprotein subfractions from these liver perfusions. ${ }^{3}$ Therefore, it is unlikely that isolation temperature artifacts cause the appearance of the unusual surfacerich and lamellar structures that we have shown in Fig. 6.

Finally, because these studies have been carried out in a nonhuman primate species in which a high correlation has been found among individuals between LDL size and the extent of coronary artery atherosclerosis (4), it seems appropriate to comment upon the potential extrapolation of these results in the primate model to the situation in human beings. In selected patients with premature coronary heart disease, Sniderman (48) has pointed out an apparent relationship between the elevated LDL apo B to cholesterol ratio and the occurrence of coronary artery atherosclerosis. Krauss and Burke (35) have demonstrated a remarkable degree of variability in the heterogeneity of LDL among individuals. Kesaniemi and Grundy (49) have carried out kinetic studies of LDL turnover in patients that suggest a significant degree of variability in LDL apo B production rates. These studies in human beings emphasize the heterogeneity among individuals in the types and amounts of LDL present and their relationships to coronary heart disease. The heterogeneity in LDL described among African green monkeys $(1,4)$ appears to be part of a similar process. The findings presented here in perfused monkey livers suggest that much of the LDL heterogeneity may be related to the secretory products of the liver, most of

\footnotetext{
${ }^{3}$ Johnson, F. L., R. W. St. Clair, and L. L. Rudel. Unpublished observations.
} 
which appear to require significant intravascular remodeling before obtaining the composition typical of plasma LDL. These data would appear to establish a potentially important role for the liver in determining the extent of plasma LDL heterogeneity.

\section{ACKNOWLEDGMENTS}

The authors appreciate the excellent technical assistance of Steve Sohn, Ramesh Shah, and Larry West, and we thank Ms. Shirley Pegram for typing the manuscript.

This work was supported by National Heart, Lung, and Blood Institute Specialized Center of Research in arteriosclerosis grant 14164 .

\section{REFERENCES}

1. Rudel, L. L., L. L. Pitts, and C. A. Nelson. 1977. Characterization of plasma low density lipoproteins of nonhuman primates fed dietary cholesterol. J. Lipid Res. 18:211-222.

2. Rudel, L. L., C. W. Leathers, M. G. Bond, and B. C. Bullock. 1981. Dietary ethanol-induced modifications in hyperlipoproteinemia and atherosclerosis in nonhuman primates (Macaca nemestrina). Arteriosclerosis. 1:144155.

3. Rudel, L. L. 1980. Plasma lipoproteins in atherogenesis in nonhuman primates. In Use of Nonhuman Primates in Cardiovascular Research. S. S. Kalter, editor. University of Texas Press, Austin. 37-57.

4. Rudel, L. L., and B. C. Bullock. 1981. Low density lipoprotein-atherosclerosis relationships in African green monkeys. Fed. Proc. 40:345a. (Abstr.)

5. Eisenberg, S., and R. I. Levy. 1975. Lipoprotein metabolism. Adv. Lipid Res. 13:1-89.

6. Sigurdsson, G., A. Nicoll, and B. Lewis. 1975. Conversion of very low density lipoprotein to low density lipoprotein. A metabolic study of apolipoprotein B kinetics in human subjects. J. Clin. Invest. 56:1481-1490.

7. Soutar, A. K., N. B. Myant, and G. R. Thompson. 1977. Simultaneous measurement of apolipoprotein-B turnover in very-low- and low-density lipoproteins in familial hypercholesterolemia. Atherosclerosis. 28:247256.

8. Berman, M., M. Hall III, R. I. Levy, S. Eisenberg, D. W. Bilheimer, R. D. Phair, and R. H. Goebel. 1978. Metabolism of apoB and apoC lipoproteins in man: kinetic studies in normal and hyperlipoproteinemic subjects. J. Lipid Res. 19:38-56.

9. Fidge, N. H., and P. Poulis. 1978. Metabolic heterogeneity in formation of low density lipoprotein from very low density lipoprotein in rat: evidence for independent production of a low density lipoprotein subfraction. $J$. Lipid Res. 19:342-349.

10. Illingworth, D. R. 1975. Metabolism of lipoproteins in nonhuman primates. Studies on the origin of low density lipoprotein apoprotein in the plasma of the squirrel monkey. Biochim. Biophys. Acta. 388:38-51.

11. Nakaya, N., B. H. Chung, and O. D. Taunton. 1977. Synthesis of plasma lipoproteins by the isolated perfused liver from the fasted and fed pig. J. Biol. Chem. 252:5258-5261.

12. Nakaya, N., B. H. Chung, J. R. Patsch, and O. D. Taunton. 1977. Synthesis and release of low density lipopro- teins by the isolated perfused pig liver. J. Biol. Chem. 252:7530-7533.

13. Swift, L. L., N. R. Manowitz, G. D. Dunn, and V. S. LeQuire. 1980. Isolation and characterization of hepatic Golgi lipoproteins from hypercholesterolemic rats. $J$. Clin. Invest. 66:415-425.

14. Swift, L. L., P. D. Soule, and V. S. LeQuire. 1982. Hepatic Golgi lipoproteins-precursors to plasma lipoproteins in hypercholesterolemic rats. J. Lipid Res. 23:962971 .

15. Noel, S. P., L. Wong, P. J. Dolphin, L. Dory, and D. Rubinstein. 1979. Secretion of cholesterol-rich lipoproteins by perfused livers of hypercholesterolemic rats. $J$. Clin. Invest. 64:674-683.

16. Guo, L. S. S., R. L. Hamilton, R. Ostwald, and R. J. Havel. 1982. Secretion of nascent lipoproteins and apolipoproteins by perfused livers of normal and cholesterol-fed guinea pigs. J. Lipid Res. 23:543-555.

17. Rudel, L. L., J. A. Reynolds, and B. C. Bullock. 1981. Nutritional effects on blood lipid and HDL cholesterol concentrations in two subspecies of African green monkeys (Cercopithecus aethiops). J. Lipid Res. 22:278-286.

18. Hamilton, R. L., M. N. Berry, M. C. Williams, and E. M. Severinghaus. 1974. A simple and inexpensive membrane "lung" for small organ perfusion. J. Lipid Res. 15:182-186.

19. Rudel, L. L., J. A. Lee, M. D. Morris, and J. M. Felts. 1974. Characterization of plasma lipoproteins separated and purified by agarose-column chromatography. Biochem. J. 139:89-95.

20. Melchior, G. W., and L. L. Rudel. 1978. Heterogeneity in the low density lipoproteins of cholesterol-fed African green monkeys (Cercopithecus aethiops). Biochim. Biophys. Acta. 531:331-343.

21. McFarlane, A. S. 1964. Metabolism of plasma proteins. In Mammalian Protein: Metabolism. H. N. Murro and J. B. Allison, editors. Academic Press, Inc., New York. 1:331-338.

22. Bilheimer, D. W., S. Eisenberg, and R. I. Levy. 1972. The metabolism of very low density lipoprotein proteins. I. Preliminary in vitro and in vivo observations. Biochim. Biophys. Acta. 260:212-221

23. Rush, R. L., L. Leon, and J. Turrell. 1971. Automated simultaneous cholesterol and triglyceride determination or the AutoAnalyzer II instrument. In Advances in $\mathrm{Au}$ tomated Analysis: Technicon International Congress. $\dot{E}$. Barton, editor. Futura Publishing Co., Mt. Kisco, NY. 503-507.

24. Rosseneu M., N. Vinaimont, R. Vercaemst, W. Dekeersgieter, and F. Belpaire. 1981. Standardization of immunoassays for the quantitation of plasma apoB protein. Anal. Biochem. 116:204-210.

25. Rudel, L. L., and M. D. Morris. 1973. Determination of cholesterol using o-phthalaldehyde. J. Lipid Res. 14:364366 .

26. Fiske, C. A., and Y. Subbarow. 1925. The colorimetric determination of phosphorus. J. Biol. Chem. 66:375400 .

27. Lowry, O. A., N. J. Rosebrough, A. L. Farr, and R. J. Randall. 1951. Protein measurement with the Folin phenol reagent. J. Biol. Chem. 193:265-275.

28. Kashyap, M. L., B. A. Hynd, and K. Robinson. 1980. A rapid and simple method for measurement of total protein in very low density lipoproteins by the Lowry assay. J. Lipid Res. 21:491-495.

29. Skipski, V. P., and M. Barclay. 1969. Chromatography of lipids. Methods Enzymol. 1:530-598. 
30. Sardesai, V. M., and J. A. Manning. 1968. The determination of triglycerides in plasma and tissues. Clin. Chem. 14:156-161.

31. Rudel, L. L., R. Shah, and D. G. Greene. 1979. Study of the atherogenic dyslipoproteinemia induced by dietary cholesterol in rhesus monkeys (Macaca mulatta). J. Lipid Res. 20:55-65.

32. Goldberg, I. J., A. N. Le, H. N. Ginsberg, J. R. Paterniti, W. V. Brown. 1981. Evidence for direct production of apolipoprotein $B$ in low density lipoprotein in the cynomolgus monkey. Arteriosclerosis. 1:378a. (Abstr.)

33. Fisher, W. R., M. G. Hammond, and G. L. Warmke. 1972. Measurements of the molecular weight variability of plasma low density lipoproteins among normals and subjects with hyper- $\beta$-lipoproteinemia. Demonstration of macromolecular heterogeneity. Biochemistry. 11:519525.

34. Hammond, M. G., M. C. Mengel, G. L. Warmke, and W. R. Fisher. 1977. Macromolecular dispersion of human plasma low density lipoproteins in hyperlipoproteinemia. Metab. Clin. Exp. 26:1231-1242.

35. Krauss, R. M., and D. J. Burke. 1982. Identification of multiple subclasses of plasma low density lipoproteins in normal humans. J. Lipid Res. 23:97-104.

36. Nelson, C. A., R. E. Casali, and M. D. Morris. 1979. The characterization of serum lipoproteins from portacaval shunted Macaca fascicularis monkeys. Biochem. Med. 22:110-118.

37. Hamilton, R. L., M. C. Williams, C. J. Fielding, and R. J. Havel. 1976. Discoidal bilayer structure of nascent high density lipoproteins from perfused rat liver. J. Clin. Invest. 58:667-680.

38. Torsvik, H., M. H. Solaas, and E. Gjone. 1970. Serum lipoproteins in plasma lecithin:cholesterol acyltransferase deficiency, studied by electron microscopy. Clin. Genet. 1:139-150.

39. Forte, T., K. R. Norum, J. A. Glomset, and A. V. Nichols. 1971. Plasma lipoproteins in familial lecithin:cholesterol acyltransferase deficiency. Structure of low and high density lipoproteins as revealed by electron microscopy. J. Clin. Invest. 50:1141-1148.
40. Glomset, J. A., and K. R. Norum. 1973. The metabolic role of lecithin:cholesterol acyltransferase: perspective from pathology. Adv. Lipid Res. 11:1-65.

41. Tall, A. R., D. M. Small, D. Atkinson, and L. L. Rudel. 1978. Studies on the structure of low density lipoproteins isolated from Macaca fascicularis fed an atherogenic diet. J. Clin. Invest. 62:1354-1363.

42. Goodman, D. S., D. Deykin, and T. Shiratori. 1964. The formation of cholesterol esters with rat liver enzymes. J. Biol. Chem. 239:1335-1345.

43. Glomset, J. A. 1962. The mechanism of the plasma cholesterol esterification reaction: plasma fatty acid transferase. Biochim. Biophys. Acta. 65:128-135.

44. Sparks, C. E., and J. B. Marsh. 1981. Metabolic heterogeneity of apolipoprotein $\mathrm{B}$ in the rat. J. Lipid Res. 22:519-527.

45. Klein, R. L., and L. L. Rudel. 1983. Effect of dietary cholesterol level on the composition of thoracic duct lymph lipoproteins isolated from nonhuman primates. J. Lipid Res. 24:357-367.

46. Puppione, D. L., S. T. Kunitake, R. L. Hamilton, M. L. Phillips, V. N. Schumaker, and L. D. Davis. 1982. Characterization of unusual intermediate density lipoproteins. J. Lipid Res. 23:283-290.

47. Parks, J. S., D. Atkinson, D. M. Small, and L. L. Rudel. 1981. Physical characterization of lymph chylomicra and very low density lipoproteins from nonhuman primates fed saturated dietary fat. J. Biol. Chem. 256:1299112999.

48. Sniderman, A., S. Shapiro, D. Marpole, B. Skinner, B. Teng, and P. O. Kwiterovich, Jr. 1980. Association of coronary atherosclerosis with hyperapobetalipoproteinemia [increased protein but normal cholesterol levels in human plasma low density $(\beta)$ lipoproteins]. Proc. Natl. Acad. Sci. USA. 77:604-608.

49. Kesaniemi, Y. A., and S. M. Grundy. 1982. Significance of low density lipoprotein production in the regulation of plasma cholesterol level in man. J. Clin. Invest. 70:1322. 